\title{
Red Tide Detection Technique by Using Multi-temporal GOCI Level 2 Data
}

\author{
Su-Ho Bak ${ }^{1}$, Heung-Min Kim ${ }^{1}$, Do-Hyun Hwang ${ }^{1}$, Seung-Yeol Oh${ }^{1}$ and \\ Hong-Joo Yoon ${ }^{*}$ \\ ${ }^{1}$ Major in the division of Earth's Environmental System Science of Spatial \\ Information Engineering, Pukyong National University, (48513) 45, Yongso-ro, \\ Nam-Gu, Busan, South Korea \\ ${ }^{1}$ yoonhj@pknu.ac.kr*
}

\begin{abstract}
This research compared absorption coefficients using multi-temporal COMS/GOCI Level 2 products. Also, through difference of absorption property which exists between satellite images in a time when a HAB did not occur and other satellite images in a time when a HAB occurred, a new red tide index has been developed. It was compared with outcomes of the red tide index of GOCI Level 2 data. At the result of comparing the GRI and RI, though areas with high values in all of the GRI and RI show a similar tendency. In case of the red tide index proposed in the study, it has a tendency to be overestimated compared with the existing red tide index of GOCI. But, in case of applying to images of no red tides, it could be confirmed that areas of wrong detection have been improved greatly in high concentration of suspended solid. The GRI can be available as a red tide index like the RI. Later, using the red tide index, it is judged that they will contribute to accuracy improvement of the detection technique of red tides.
\end{abstract}

Keywords: Ocean Color Remote Sensing, Harmful Algal Blooms, GOCI, Red tide, Red tide detection

\section{Introduction}

A red tide is a phenomenon that color of sea water changes by mass propagation of microbes like phytoplankton in a special condition [1]. Recently, besides a red tide changing the color of sea water, although the color of sea water is not changed, as long as physical damage becomes injurious to other creatures, it is defined as harmful algal bloom (HAB) in a concept of full bloom of harmful algae [2]. In Korea, the red tide has harmed Korea in annual average damage of 7.2 million dollars for the last 20 years from the start of the greatest damage of 66.3 million dollars in 1995.

Studies of red tides so far have been realized focused on environmental and physiological properties about species causing red tides [3-5]. But, because recent red tides receive influence of complex factors due to change of marine environment and development of coastal waters, occurrence and progressing aspects of red tides become complex. Moreover, it is more difficult to predict the occurrence of red tides because red tides occurring along the shores of Korea are clear in seasonal transition of species [6]. So, it can be effective to detect the occurrence quickly and minimize damages by it is field research using a ship or an airplane. But, there are disadvantages that it costs a lot of money economically and does not monitor wide coasts effectively. Therefore, necessity of remote sensing using a satellite comes to the fore [8].

Studies on detecting and monitoring red tides using remote sensing of satellites have been tried based on chlorophyll-a concentration which was gained from the satellites [9-

Received (June 12, 2017), Review Result (September 29, 2017), Accepted (October 3, 2017) 
10]. However, in case of detecting red tides based on chlorophyll-a concentration, there is a weak point that photosynthesis is not realized sufficiently or a red tide with low concentration cannot be detected. To overcome the limitation of studies of detecting red tides based on chlorophyll-a concentration by satellites, there have been trial to divide red tides by grasping optical properties of sea water $[7,11]$. Kim et al. detected red tides in areas with clear water based on normalized water leaving radiance of MODIS level 2 data and spectrums of red tides in field. Son et al. detected red tides which occurred in clear water and turbid water based on water leaving radiance of GOCI level 2 data and spectrums of red tides in field. But, these methods are algorithms which detected red tides by using normalized water leaving radiance but contain errors. As optical characteristics of sea water which can be obtained using a real satellite, there are absorption coefficients and back-scattering coefficients besides normalized water leaving radiance. If the characteristics are used, they will be helpful for lessening errors of algorithms which were developed by normalized water leaving radiance.

However, it is in a situation that field investigation data on the optical characteristics except normalized water leaving radiance about species causing red tides off the south coast of Korea are lacking. Therefore, this study has developed a technique to detect red tides using absorption coefficients in waters where red tides occurs without field observation values, applied it to some cases, and verified it compared with existing developed red tide index algorithms.

\section{Data and Methodology}

\subsection{Study Area and Period}

In this study, referring to data of breaking news [12] of red tides of National Institute of Fisheries Science, the south sea of Korea where red tides happen frequently was selected as the study area (Figure 1).

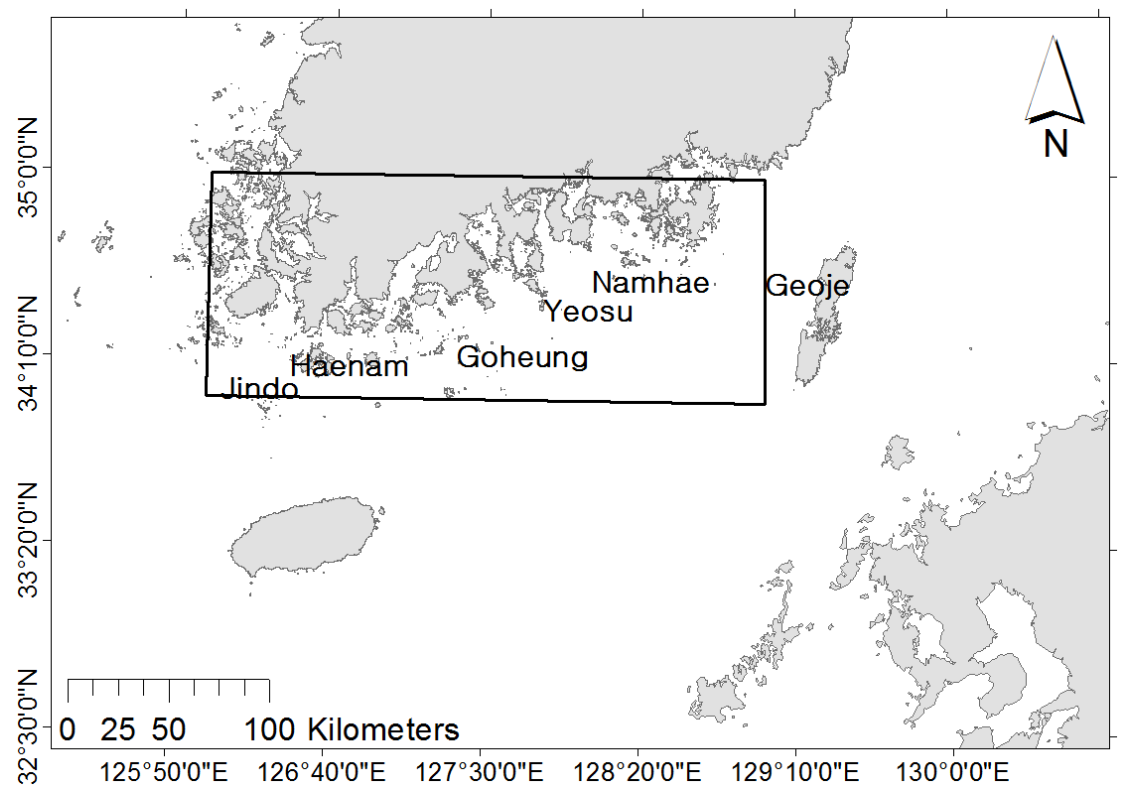

Figure 1. Study Area

The region contains Goheung, Yeosu, and Namhae where red tides occur very often and is an area pertinent to Case 2 water in the optical properties of sea water due to suspended substances and dissolved organic matters. 
The study period was chosen from 2012 to 2015 except 2011 when red tides did not occur among 2011 to the present when images of Geostationary Ocean Color Imager (GOCI) have been provided.

\subsection{Data}

The study referred to the data of breaking news of red tides of the National Institute of Fisheries Science. As test materials, GOCI level 2 data provided by Communication, Ocean and Meteorological Satellite (COMS) were used.

GOCI is a marine payload of COMS and is composed of six bands of the visible light region and two bands of the near-infrared light region. Spatial resolution of GOCI is $500 \mathrm{~m}$. On the basis of Korean Standard Time, a total of eight images were taken per one hour after hour from 9 to 16 .

From acquiring level 1B data of GOCI, using GOCI Data Processing System (GDPS), atmospheric correction was made. At the result, level 2B containing products of absorption coefficients was used among calculated data of level 2A, 2B, 2C, and 2P.

Satellite images on days when red tides occurred made reference to the data of breaking news of red tides of the National Institute of Fisheries Science. Images of 30 days from the starting day that a red tide warning was issued were acquired. About satellite images of days with no red tides, satellite images from January to May when it is difficult for tides to happen were acquired. With the exception of images which are difficult to get data due to clouds, the rest of them were used.

\subsection{Method}

Bak et al., (2016) [13] confirmed that absorption coefficients became noticeably low in case of the occurrence of a red tide near sea areas of Goheung by using Landsat-7 ETM+ images and COMS/GOCI images. At the result of expanding the outcome into the whole sea areas of the southern sea of Korea excluding sea areas near Goheung as a target region of a previous study, it could be confirmed that the number of pixels with relatively high absorption coefficients lessened remarkably on images shot at the time when a red tide happened (Figure 2).

When seeing (Figure 2), in case of satellite images taken at the time when a red tide occurred, the number of pixels with relatively high absorption coefficients lessened conspicuously. It is judged that this is a result that high values were removed as much as the number of pixels relevant to the sea areas where a red tide occurred on all the images because absorption coefficients came to be lower in case of the occurrence of a red tide as presented in the advanced study. When the decrease of absorption coefficients was checked by band unit, there were great changes in band $1(412 \mathrm{~nm})$, band $2(443 \mathrm{~nm})$, and band $3(490 \mathrm{~nm})$.

In particular, as they decreased drastically in band $1(412 \mathrm{~nm})$, there was a characteristic to show a similar value like band $2(443 \mathrm{~nm})$ [13]. If the ratio of two bands is represented into a formula, it can be expressed like the next Formula (1).

$$
\frac{a_{412}-a_{443}}{a_{412}+a_{443}}
$$

$$
a_{412}: \text { Absorption coefficient at } 412 \mathrm{~nm}
$$

$a_{443}$ : Absorption coefficient at $443 \mathrm{~nm}$ 

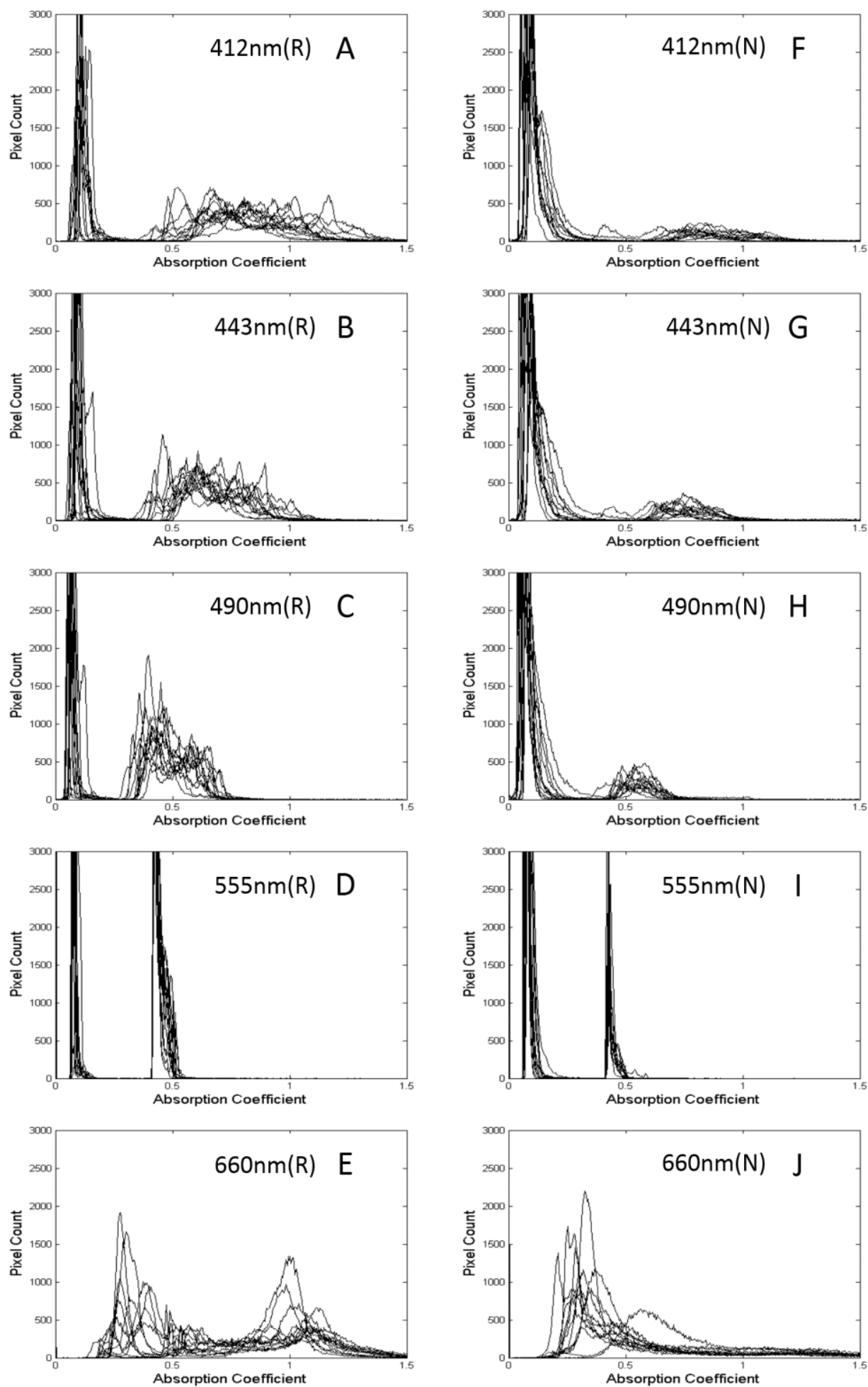

Figure 2. Histogram of Absorption Coefficient per Band in the Time of NonOccurrence of a Red Tide(N) and Histogram of an Absorption Coefficient per Band in the Time of the Occurrence of a Red Tide(R)

Using the formula, when it is applied to images shot in the time of the non-occurrence of a red tide and other images shot in the time of the occurrence of a red tide, it can be known that in case of the non-occurrence of a red tide, values of pixels are distributed in 
the range of positive numbers, however, in case of the occurrence of a red tide, values of pixels are distributed in the range of negative numbers (Figure 3-4).

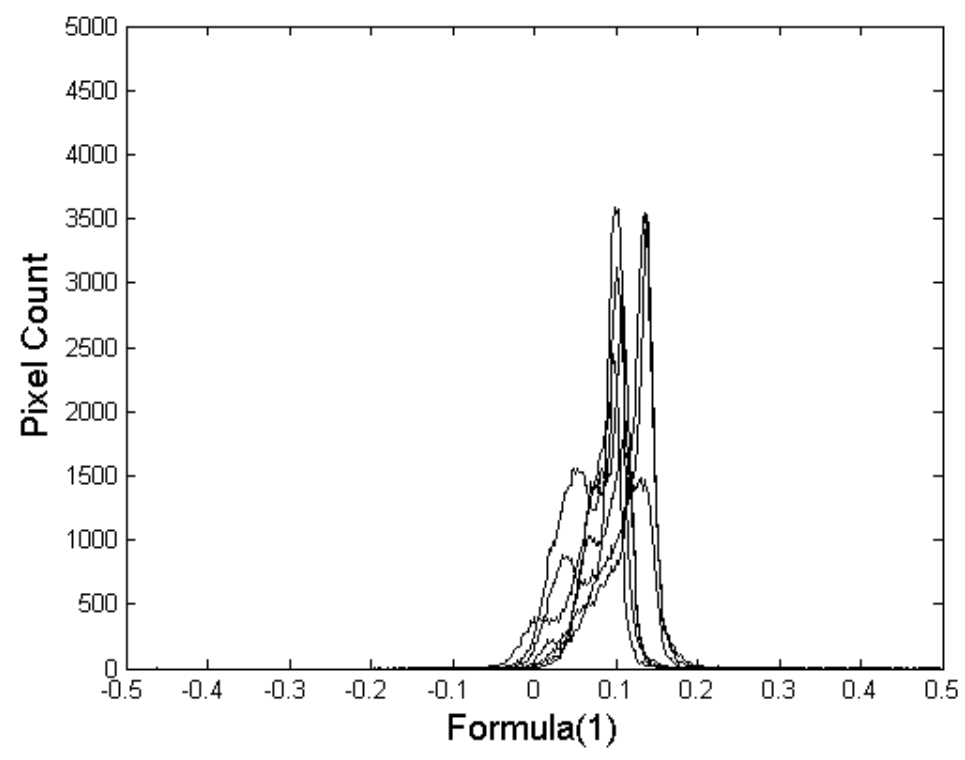

Figure 3. Distribution of Pixel Values of Satellite Image on Non-Red Tide Occurred. In Case of the Non-Occurrence of Red Tide, at the Result of Applying Formula (1) to all the Image, the Values are Distributed in Positive Values (Operation Result $<0$ )

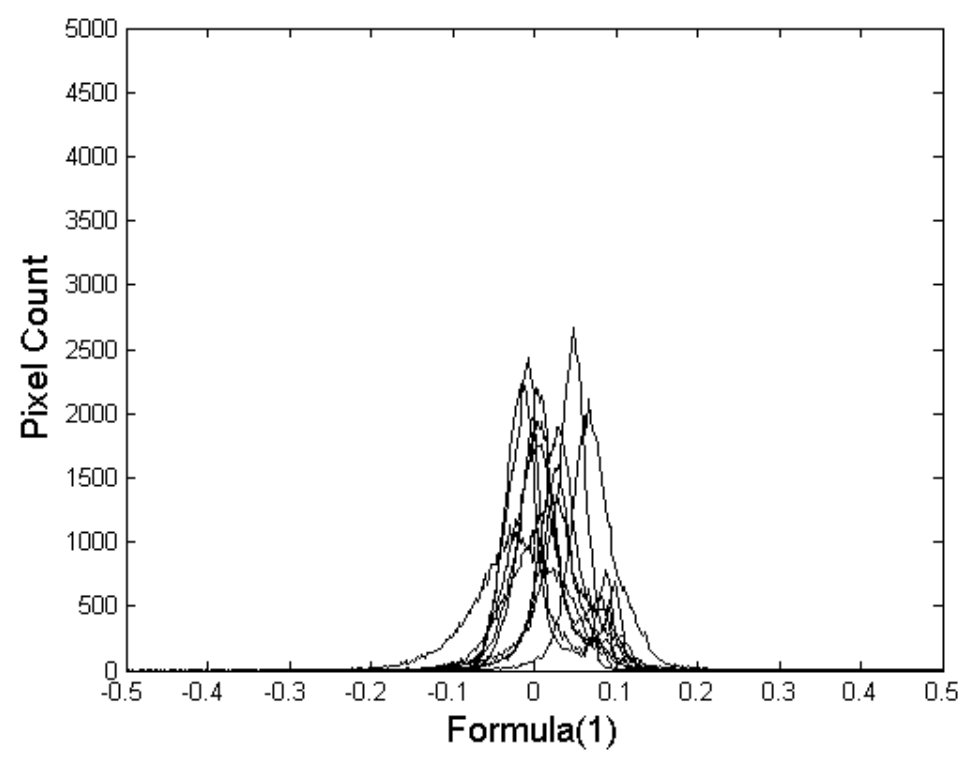

Figure 4. Distribution of Pixel Values of Satellite Image on Red Tide Occurred. In Case of the Occurrence of a Red Tide, at the Result of Applying Formula(1) to all the Images, the Values are Distributed in Negative Values ( $0<$ Operation Result)

The GOCI Red Tide Index which was made by using the optic characteristics is like the next Formula (2). 


$$
\begin{array}{r}
G R I=-\frac{a_{412}-a_{443}}{a_{412}+a_{443}}=\frac{a_{443}-a_{412}}{a_{443}+a_{412}} \\
a_{412}: \text { Absorption coefficient at Band } 1(412 \mathrm{~nm}) \\
a_{443}: \text { Absorption coefficient at Band } 2(443 \mathrm{~nm})
\end{array}
$$

\section{Result}

(Figure $5,7,9,11$ ) is a result that the GRI was calculated by using the image of GOCI on Aug. 13-15, 2013 and Sep. 1, 2014 when a red tide occurred off the south coast of Korea. In (Figure 6, 8, 10,12), using the same image, from calculating the RI (Red Tide Index) of Ahn et al., (2006), pixels with values from 0 to 50 are presented.

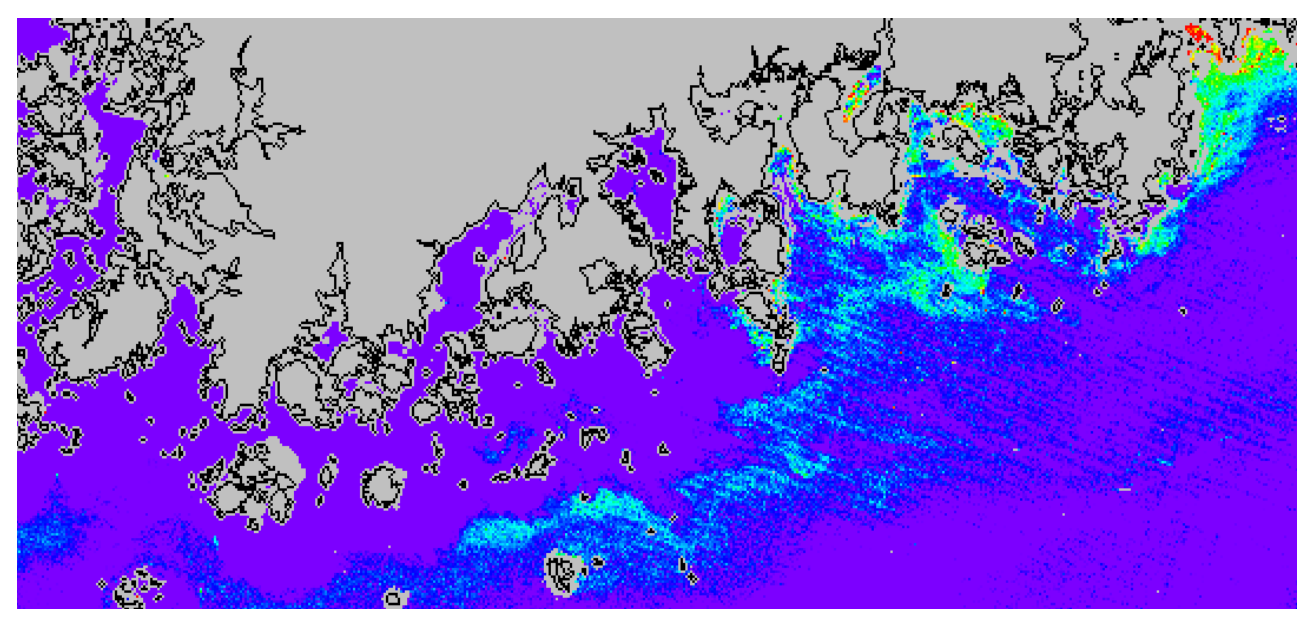

\section{Figure 5. Operation Result that the GRI was applied to the Image of GOCI on August 13, 2013}

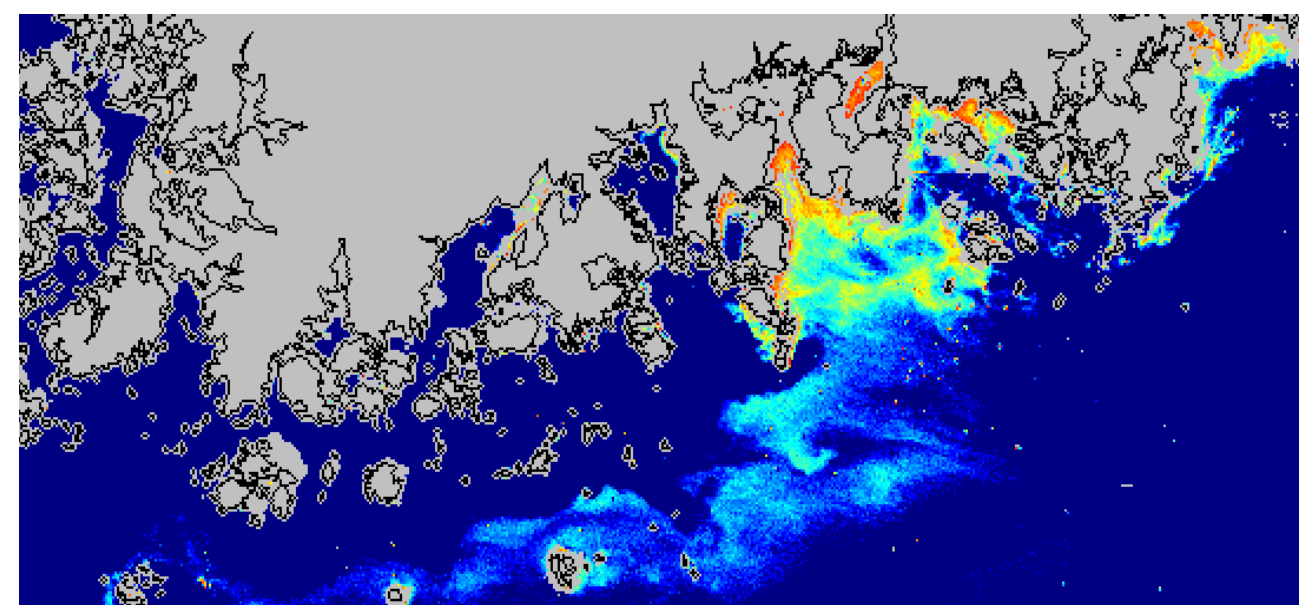

Figure 6. Operation Result that the RI was applied to the Image of $\mathrm{GOCl}$ on August 13, 2013 


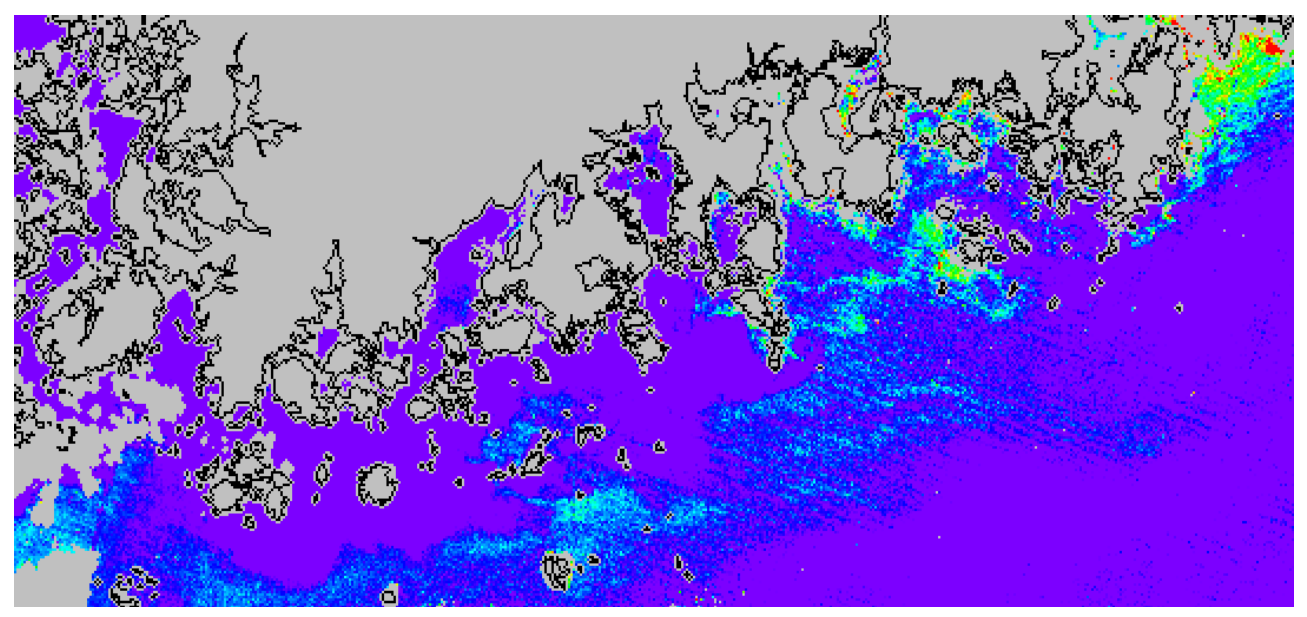

Figure 7. Operation Result that the GRI was applied to the Image of GOCI on August 14, 2013

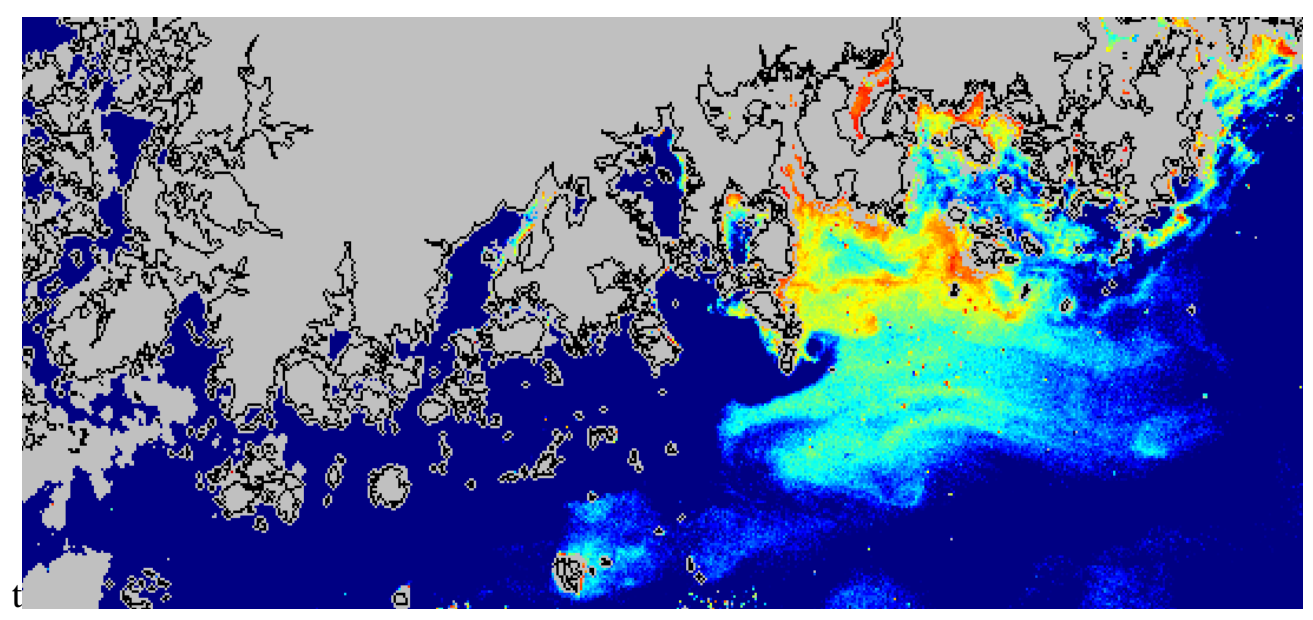

Figure 8. Operation Result that the RI was applied to the Image of $\mathrm{GOCI}$ on August 14, 2013

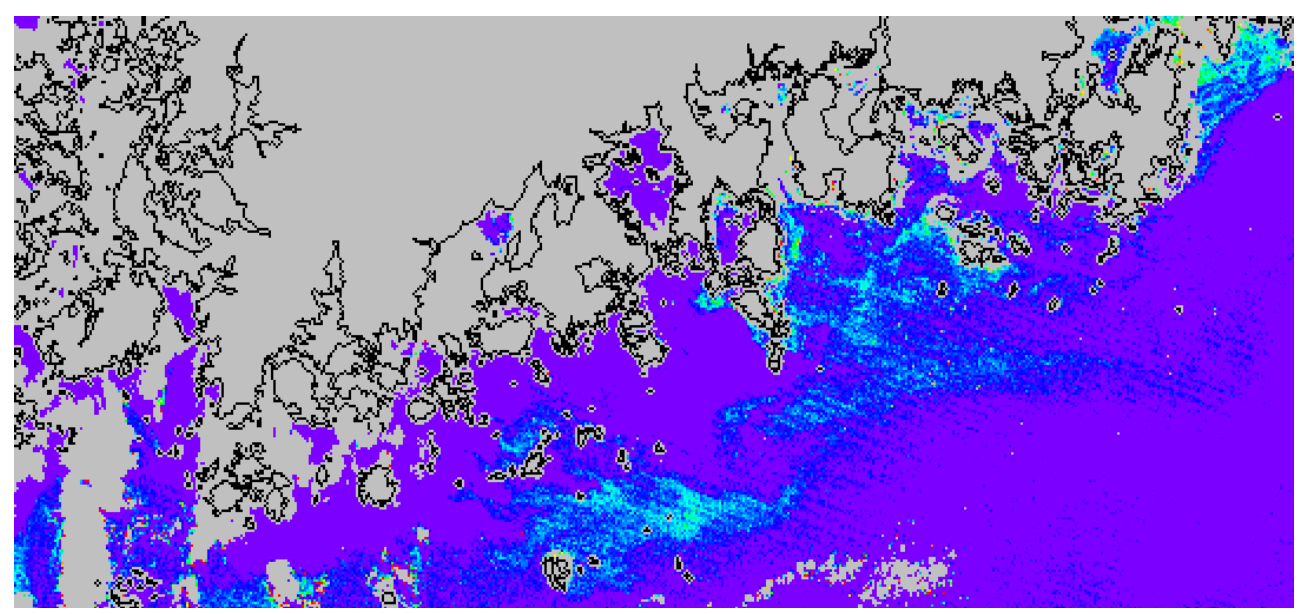

Figure 9. Operation Result that the RI was applied to the Image of $\mathrm{GOCl}$ on August 15, 2013 


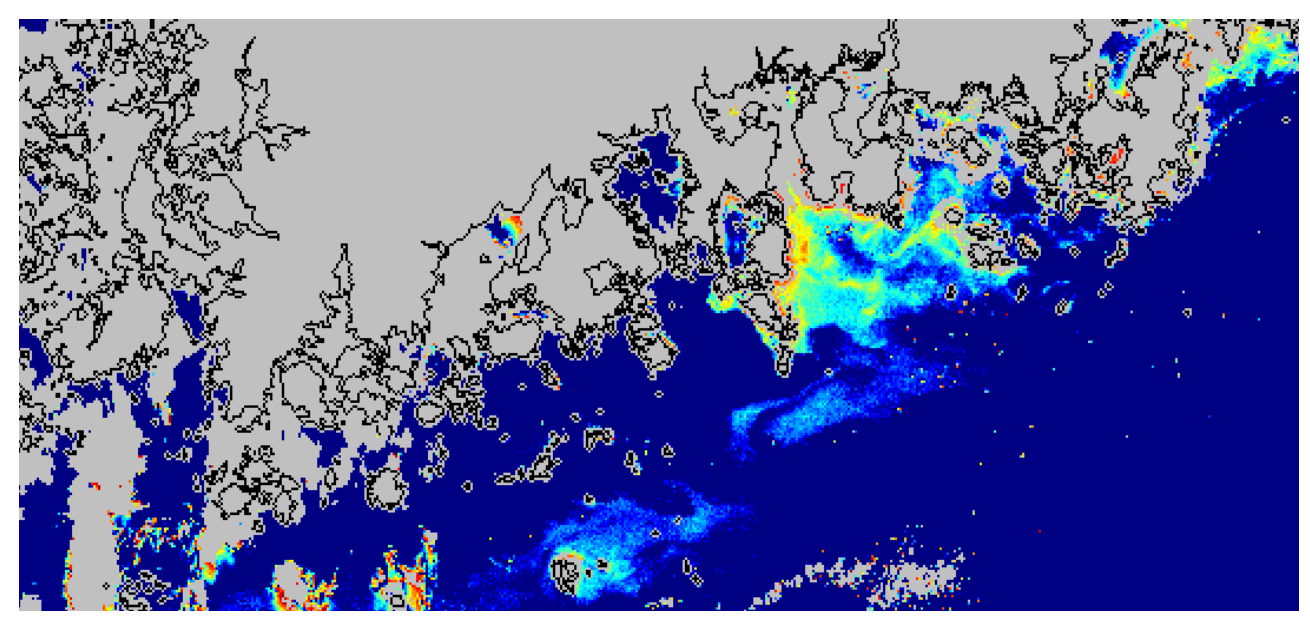

Figure 10. Operation Result that the RI was applied to the Image of GOCI on August 15, 2013

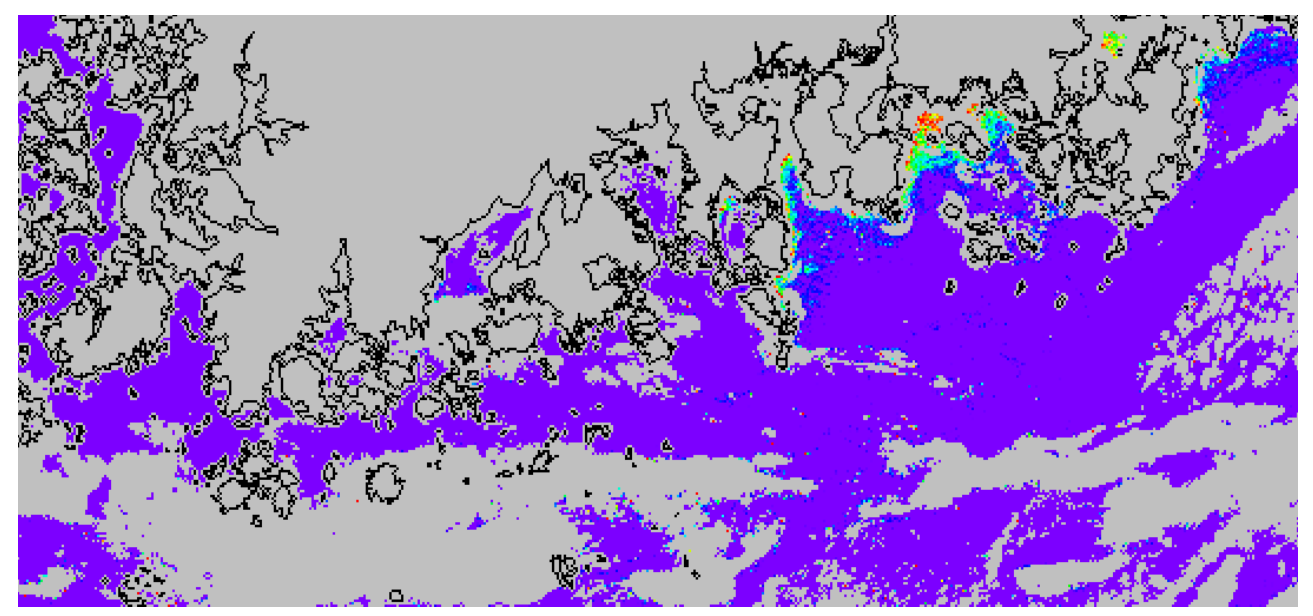

Figure 11. Operation Result that the GRI was applied to the Image of GOCI on September 1, 2014

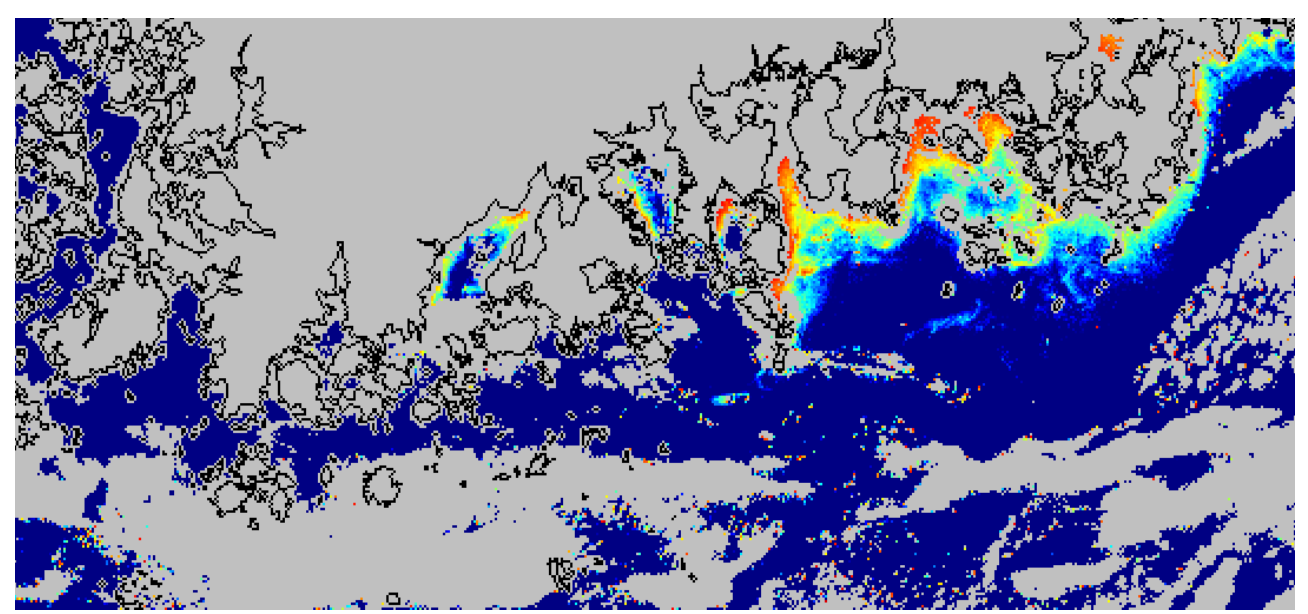

Figure 12. Operation Result that the RI was applied to the Image of GOCI on September 1, 2014

Compared to Figure 6 and Figure 7, RI was detected a wider area than the GRI. But the most of case, GRI was detected a wider area than the RI. 
At the result of comparing the GRI and RI, though sea areas with high values in all of the GRI and RI show a similar tendency, the result which was calculated by the GRI was overestimated relatively. But GRI was more accurate than the RI in high concentration of suspended solids area.

Next (Figure 13) is a result that the GRI was calculated using the image of GOCI on March 3, 2013 when a red tide did not occur. (Figure 14) is an image that the RI was calculated with the same image.

In case of the GRI, the rest sea areas except some pixels were calculated with low values. But, in case of the RI, highly calculated pixels exist in coastal areas. Also, far in the sea, there were high calculated pixels compared with neighboring waters.

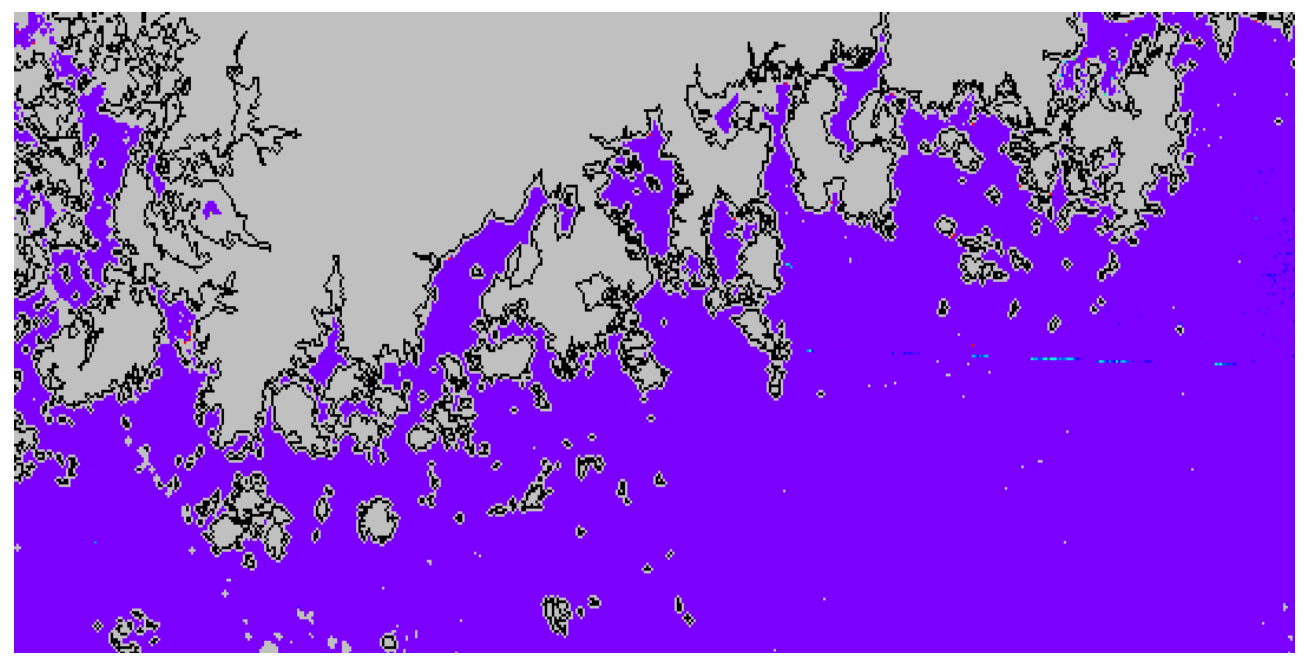

Figure 13. Result that the GRI was applied to the Image of GOCl on March 3, 2013

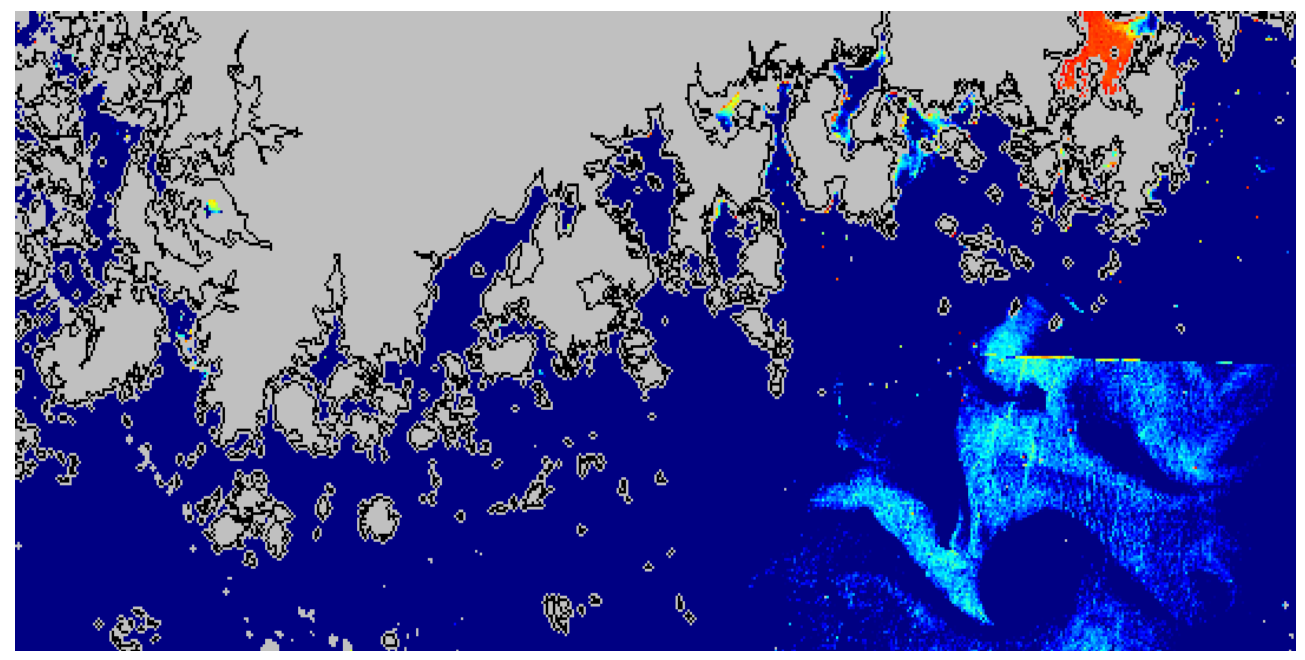

Figure 14. Result that the RI was applied to the Image of GOCI on March 3, 2013

\section{Conclusion and Discussion}

This paper presented the GRI (GOCI Red Tide Index) from comparatively analyzing satellite images which were shot in the time that a red tide did not occur and other images which were shot in the time that a red tide occurred. In case of the GRI, when it was applied to satellite images shot in the occurrence of a red tide, there was the tendency of 
overestimation compared with the RI. When it was applied to satellite images shot in the non-occurrence of a red tide, there was the result that the range of wrong detection has been improved compared with the RI.

Through the result, it is judged that the GRI can be available as a red tide index like the RI. Plus, using this as a characteristic of red tide pixels, if it is mixed with other optical properties of red tides which were used in the existing methods of red tides, it will heighten detection accuracy more.

But, in case of the GRI which was proposed in this study, because it was made based on optical properties which uniquely existed in the time when a red tide occurred, it cannot necessarily say that optical properties of red tides are included. Later, based on data about whether real red tides exist or not and density of red tides which were acquired on spots, if absorption spectrums can be obtained, it is judged that more reliable result can be gained.

\section{Acknowledgments}

This paper is a revised and expanded version of a paper entitled "Study on Red Tide Detection Technique Using Satellite Images in Different Times" presented at 2016 The $5^{\text {th }}$ International Conference on Next Generation Computer and Information Technology at Harbin on Aug. 19-20.

This work was financially supported by the BK21 plus Project of the Graduate School of Earth Environmental Hazard System.

\section{References}

[1] H. Kim, S. Lee and G. Ahn, "Red tide in Korean coast - causes and prevention of recently red tide", National Institute of Fisheries Science, Busan, (1997).

[2] D. Anderson, P. Anderson, V. Bricelj, J. Cullen and J. Rensel, "Monitoring and Management Strategies for Harmful Algal Blooms in Coastal Waters", Intergovernmental Oceanographic Commission Technical Series, Paris, (2001).

[3] M. Lee, "Characteristics of Long-term Water Quality Variations and Cochlodinium polykrikoides Blooms in the Mid-southern Coastal waters of Korea", Journal of the Korean Society for Marine Environmental Engineering., vol. 14, no. 1, (2011), pp. 19-31.

[4] E. Cho, "Comparative Study on Outbreak and Non-outbreak of Cochlodinium Polykridoides Margalef in South Sea of Korea in 2007-2009", Journal of the Korean Society for Marine Environment \& Safety, vol. 16 , no. 1 , (2010), pp. 31-41.

[5] M. Cho and J. Moon, "Marine Environments in the Neighborhood of the Narodo as the First Outbreak Region of Cochlodinium polykrikoides Blooms", Journal of the Korean Society for Marine Environmental Engineering, vol. 11, no. 3, (2008), pp. 113-123.

[6] H. Kim, "Harmful Algal Blooms in the Sea", Dasom Publishing Co., Busan, (2005).

[7] Y. Kim, Y. Byun, Y. Huh and K. Yu, "Detection of Cochlodinium Polykrikoides Red Tide Using MODIS Level 2 Data in Coastal Waters", KSCE Journal of Civil Engineering, vol. 27, no. 4, (2007), pp. 535-540.

[8] S. Oh and H. Yoon, "Red-Tide Detection by using MODIS/AQUA data", Proceedings of the Korean Institute of Electronic Communication Sciences, Namwon, Korea, (2012).

[9] R. P. Stumpf, M. E. Culver, P. A. Tester, M. Tomlinson, G. J. Kirkpatrick, B. A. Pederson, E. Truby, V. Ransibrahmanakuf and M. Soracco, "Monitoring Karenia brevis blooms in the Gulf of Mexico using satellite ocean color imagery and other data", Harmful Algae, vol. 2, no. 2, (2003), pp. 147-160.

[10] M. C. Tomlinson, T. T. Wynne and R. P. Stumpf, "An evaluation of remote sensing techniques for enhanced detection of the toxic dinoflagellate, Karenia brevis", Remote sensing Environment, vol. 113, no. 3, (2009), pp. 598-609.

[11] Y. B. Son, J. Ishizaka, J. C. Jeong, H. C. Kim and T. Lee, "Cochlodinium polykrikoides red tide detection in the South Sea of Korea using spectral classification of MODIS data", Ocean Science Journal, vol. 46, no. 4, (2011), pp. 239-263.

[12] National Institute of Fisheries Science, http://www.nfrdi.go.kr.

[13] S. H. Bak and H. J. Yoon, "Analysis on optical property in the South Sea of Korea by using Satellite Image : Study of Case on red tide occurrence in August 2013", Journal of the Korean Institute of Electronic Communication Sciences, vol. 11, no. 7, (2016), pp. 723-728. 


\section{Authors}

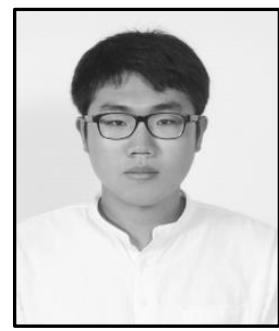

Su-Ho Bak, he received the B.S. degree from Dept. of Spatial Information Engineering of Pukyong National University, Busan in 2013. He is a graduate school student in Dept. of Spatial Information Engineering of Pukyong National University.

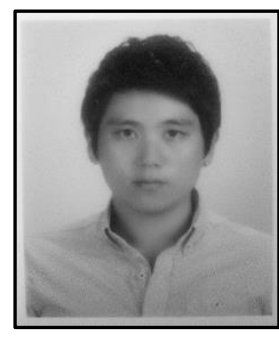

Heung-Min Kim, he received the B.S. degree from Dept. of Spatial Information Engineering of Pukyong National University, Busan in 2015. He is a graduate school student in Dept. of Spatial Information Engineering of Pukyong National University.

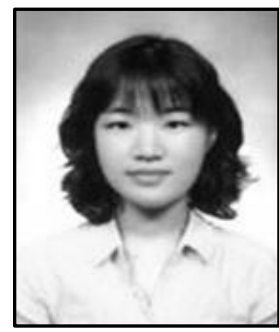

Do-Hyun Hwang, she received the M.S. degree from Dept. of Spatial Information Engineering of Pukyong National University, Busan in 2013. She's doing a Ph.D. course in Dept. of Spatial Information Engineering of Pukyong National University.

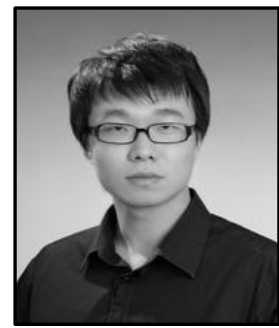

Seung-Yeol Oh, he received the M.S. degree from Dept. of Spatial Information Engineering of Pukyong National University, Busan in 2012. He's doing a Ph.D. course in Dept. of Spatial Information Engineering of Pukyong National University.

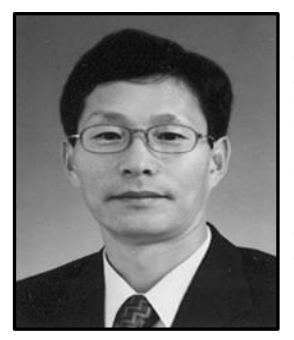

Hong-Joo Yoon, he is professor and his academic degrees are Master in Ocean Dynamics (Pukyong National University, Korea), DEA in Atmospheric Dynamics (Paris VI University, France) and Doctor in Geodynamics (Grenoble I University, France). His special fields are Satellite Remote Sensing (Satellite Oceanography and Meteorology) and Marine \& Fisheries GIS. His recently studying the main subjects are change of climate, variations of SSH\&SST, ocean circulation and application of Big data in ocean. 
International Journal of Grid and Distributed Computing Vol. 10, No. 10 (2017) 